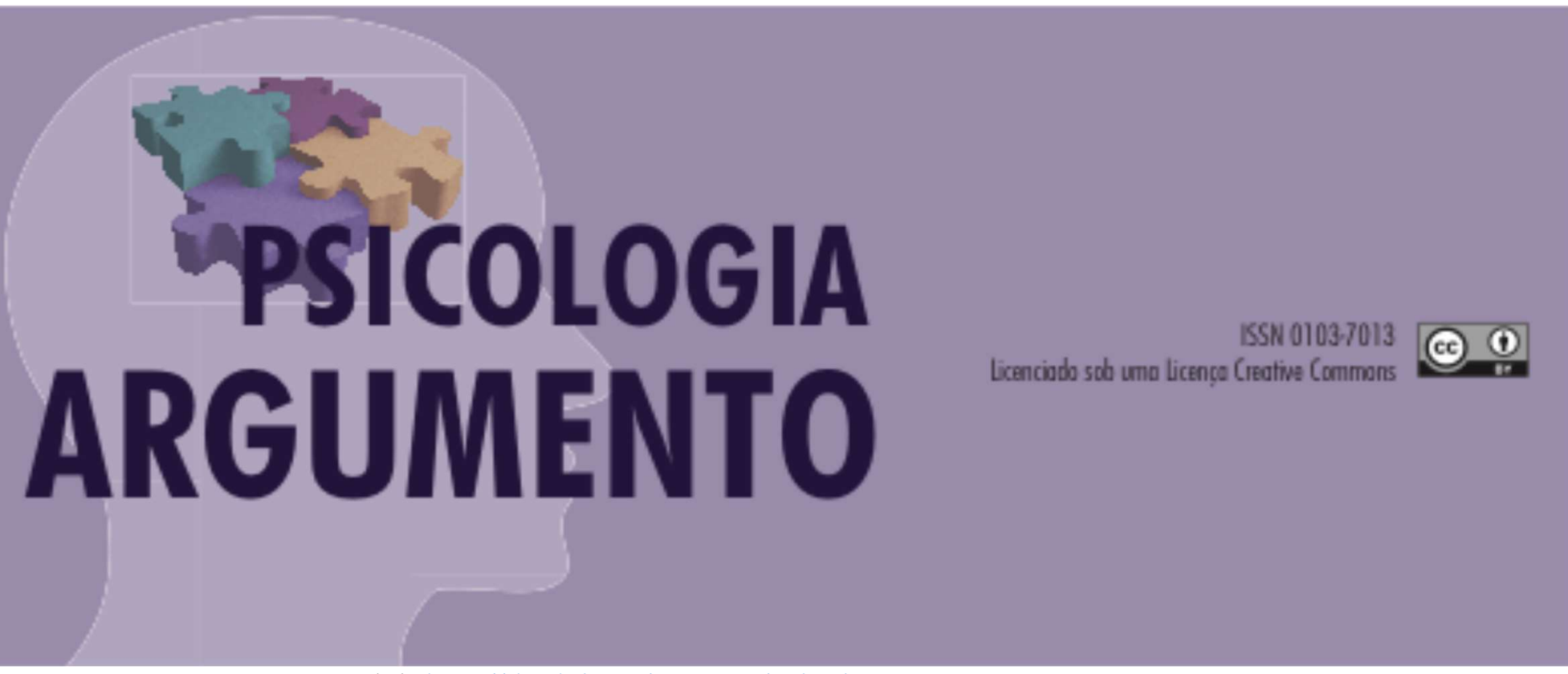

doi: http://dx.doi.org/10.7213/psicolargum.38.100.AO01

\title{
Caminhos da formação pedagógica do professor universitário
}

\author{
Training pathways of university teacher
}

Caminos de formación pedagógica de docentes universitarios

\section{Edna Liz Prigol}

Pós doutoranda em Educação na Pontifícia Universidade Católica do PR prigoledna@gmail.com Orcid: http://orcid.org/0000-0002-7449-6622

Marilda Aparecida Behrens

Professora do Programa de Pós Graduação na Pontifícia Universidade Católica do PR marildaab@gmail.com Orcid: http://orcid.org/0000-0002-3446-2321

\begin{abstract}
Resumo
As mudanças acontecem em escala mundial, podendo ser apontados, entre elas, o avanço da tecnologia da informação e comunicação, a globalização e a inovação, afetando muitas áreas, a exemplo da educação. Diante desse cenário, buscou-se investigar o seguinte problema: quais são as contribuições dos processos formativos dos docentes para uma prática pedagógica que corresponda às necessidades do mundo contemporâneo? Teve-se como objetivo identificar se os professores tiveram aproximações com os fundamentos didático-pedagógicos, analisando dados das formações inicial e continuada e do desenvolvimento profissional, identificando bases para uma prática pedagógica contemporânea. Sustentados por uma abordagem qualitativa, com opção metodológica do estudo de caso, os dados foram coletados por meio de questionário e entrevistas com nove professores de um centro universitário de Curitiba-PR. Os estudos revelaram que os professores pesquisados constroem seus conhecimentos didático-pedagógicos em geral nos cursos de especialização, sendo complementados durante a docência, em um processo de reflexão e ação, para adequar a prática pedagógica às necessidades dos alunos e do mundo contemporâneo. Palavras-chave: Educação superior; Formação docente; Prática pedagógica.
\end{abstract}

\section{Abstract}

The changes take place on a global scale, including the advancement of information and communication technology, globalization and innovation, affecting many areas, such as 
education. In view of this scenario, we sought to investigate the following problem: what are the contributions of the teachers' training processes to a pedagogical practice that corresponds to the needs of the contemporary world? The objective was to identify if the teachers had approximations with the didactic-pedagogical foundations, analyzing data of initial and continuing formal training and the professional development, identifying bases for a contemporary pedagogical practice. Based on a qualitative approach, with the methodological option of the case study, the data were collected through a questionnaire and interviews with nine professors from a university center in Curitiba-PR. The studies revealed that the teachers studied build their didactic-pedagogical knowledge in general in the specialization courses, being complemented during the teaching, in a process of reflection and action, to adapt the pedagogical practice to the needs of students and the contemporary world

Keywords: University education; Teacher formation; Pedagogical practice.

\section{Resumen}

Los cambios se producen a escala global, incluido el avance de la tecnología de la información y la comunicación, la globalización y la innovación, que afectan a muchas áreas, como la educación. En vista de este escenario, intentamos investigar el siguiente problema: cual son las contribuciones de los procesos de capacitación de los maestros a una práctica pedagógica que corresponde a las necesidades del mundo contemporáneo? El objetivo de este estudio fue identificar si los maestros tenían aproximaciones con los fundamentos didácticos y pedagógicos, analizando datos sobre la capacitación inicial y continuo y el desarrollo profesional, identificando las bases para una práctica pedagógica contemporánea. Sobre la base de un enfoque cualitativo, con la opción metodológica del estudio de caso, los datos se recopilaron a través de un cuestionario y entrevistas con nueve profesores de un centro universitario en Curitiba-PR. Los estudios revelaron que los docentes estudiados construyen su conocimiento didáctico-pedagógico en general en los cursos de especialización, complementándose durante la enseñanza, en un proceso de reflexión y acción, para adaptar la práctica pedagógica a las necesidades de los estudiantes y del mundo contemporáneo.

Palabras clave: Educación universitaria; Formación docente; Práctica pedagógica.

\section{Introdução}

Atualmente, a sociedade demanda que os profissionais, inclusive os docentes, sejam muito competentes, críticos, criativos e estejam aptos a enfrentar os desafios impostos pela contemporaneidade, que, em decorrência dos avanços científicos e tecnológicos, provocaram grandes transformações na sociedade e no mundo. Requeremse indivíduos que tenham um conjunto de habilidades e atitudes que possibilitem resolver os problemas com responsabilidade planetária, sejam inovadores, dominem as tecnologias, consigam trabalhar em grupo, respeitando a individualidade, e ainda busquem o desenvolvimento e aperfeiçoamento constante do conhecimento, uma vez que se tem clareza de que este é provisório, não está pronto e acabado, mas em permanente transformação. Para isso, faz-se necessário superar pensamentos e ações conservadores, lineares, fragmentados, absolutos, autoritários, que impossibilitam, segundo Morin 
(1999, 2008, 2012), a compreensão da complexidade da realidade e de suas relações e inter-relações com o todo.

Uma revisão histórica permite identificar que a formação inicial do docente da educação superior até o fim do século 20 pode ter se alicerçado em uma visão cartesiana mecanicista, que permitiu formar professores com habilidades para serem transmissores de conhecimento, enaltecendo a teoria, a repetição e a cópia dos conteúdos pelos acadêmicos, ficando muito distantes das necessidades exigidas na contemporaneidade de um profissional, principalmente do professor da educação superior.

O entendimento desse posicionamento conduz à compreensão de que o docente deste século precisa entender que existe a necessidade de superação do paradigma conservador na prática pedagógica, que privilegia o professor centralizador, transmissor de conhecimentos como verdades absolutas. É preciso buscar novos caminhos, que possibilitem o diálogo entre as ciências e as relações entre todos os tipos de pensamento, não como um dogma, mas como um desafio a ser enfrentado, assim como perceber a complexidade das relações existentes entre as partes e o todo, compreender a dinâmica não linear presente no conhecimento e na aprendizagem, religar, contextualizar, problematizar, em oposição ao pensamento que separa, fragmenta, simplifica e reduz a realidade e o conhecimento (Morin, 1999, 2008, 2012).

Esse cenário aponta para a necessidade de desenvolvimento de profissionais que tenham know-how para raciocinar e gestar soluções para resolver os problemas emergentes a ser enfrentados. Essas transformações vêm alterando, entre outras coisas, os papéis dos profissionais, como já afirmava Moraes (1997, p. 20) na década de 1990, pois “[...] a ciência está exigindo uma nova visão de mundo, diferente e não fragmentada. A atual abordagem que analisa o mundo em partes independentes já não funciona”. A autora continua sua observação afirmando sobre a necessidade de reestruturação geral e específica do homem e do mundo por meio da educação, que deve reconhecer "[...] a importância de diálogos que precisam ser restabelecidos, com base em um enfoque mais holístico e em um modo menos fragmentado de ver um mundo e nos posicionarmos diante dele" (Moraes, 1997, p. 20).

Diante desse desafio, o professor universitário precisa ir além do domínio de conhecimentos específicos de sua área e saber ensiná-los, compreendendo o significado e a possibilidade de fazer com que os acadêmicos se apropriem desses conteúdos e os 
utilizem para se transformar em cidadãos do mundo aptos a confrontar os desafios impostos pela sociedade.

A partir desses pressupostos, justifica-se o desenvolvimento deste estudo, para compreender quais são as contribuições dos processos formativos dos docentes para uma prática pedagógica que corresponda às necessidades do mundo contemporâneo. Dessa maneira, buscou objetivamente identificar se os professores tiveram aproximações com os fundamentos didático-pedagógicos para subsidiar a prática docente, analisando dados das formações formais e do desenvolvimento profissional, identificando assim possíveis bases para uma ação pedagógica inovadora.

\section{Caminhos metodológicos para investigar a prática pedagógica do professor da educação superior}

Com a possibilidade de conhecer e descrever os fatos, os fenômenos e o contexto do estudo, princípios da pesquisa qualitativa de natureza descritiva, optou-se por esse caminho metodológico, que "[...] envolve uma abordagem naturalista, interpretativa, para o mundo, o que significa que seus pesquisadores estudam as coisas em seus cenários naturais, tentando entender, ou interpretar, os fenômenos em termos dos significados que as pessoas a eles conferem" (Denzin e Lincoln, 2006, p. 17).

Para este trabalho, foi utilizada como estratégia de pesquisa a modalidade do estudo de caso, que, segundo Yin e Grassi (2001, p. 32), “[...] é uma investigação empírica que investiga um fenômeno contemporâneo dentro de seu contexto da vida real".

A investigação foi realizada dentro do grupo de pesquisa de um programa de stricto sensu em Educação, de uma universidade de grande porte no Brasil/Paraná. O estudo de caso foi realizado em um centro universitário, situado na cidade de Curitiba, estado do Paraná, sendo uma instituição educacional de caráter privado que oferece cursos superiores de graduação em bacharelado, licenciatura e tecnologia, nas modalidades presencial, semipresencial e a distância, além de cursos de pós-graduação lato e stricto sensu. A pesquisa Paradigma da complexidade e transdisciplinaridade como pilares epistemológicos para geração de construtos, saberes e práticas na formação pedagógica dos professores, tem aprovação do conselho de ética, na plataforma Brasil, sob Parecer: 2.580.181, envolvida no estudo, originou esse artigo. Os professores envolvidos preencheram o TCLE (termo de consentimento livre esclarecido) e aceitaram 
participar da pesquisa. $\mathrm{O}$ universo da pesquisa foram professores universitários da instituição pesquisada, para a amostragem da investigação foi definido como critério os professores que participaram integralmente das duas fases de produção de dados - o questionário e a entrevista, dessa maneira contribuíram para o estudo nove professores. Os instrumentos utilizados na investigação foram elaborados no grupo de pesquisa, no qual foram realizadas aplicações piloto para validação da proposta.

Para a coleta dos dados, foi aplicado um questionário semiestruturado com perguntas abertas e fechadas, por ser um instrumento que permite reunir um conjunto de perguntas pré-elaboradas, de forma ordenada, focadas no objetivo da pesquisa e dispostas em itens sequencialmente organizados, com o objetivo de captar respostas dos pesquisados (Chizzotti, 2003). O questionário foi entregue em mãos para cada um dos professores participantes da pesquisa, possibilitando assim fazer a leitura conjuntamente e dirimir dúvidas que pudessem surgir.

Durante o processo investigativo, foi utilizado como um segundo instrumento para a construção dos dados a entrevista, que, conforme Yin e Grassi (2001, p. 112), é "[...] uma das mais importantes fontes de informações para um estudo de caso"; reconhecendose a importância dessa afirmativa, utilizou-se a entrevista episódica. Cada entrevista foi agendada previamente com cada um dos professores participantes da pesquisa, sendo realizada em um espaço reservado na instituição de ensino e gravada para que posteriormente fosse realizada a transcrição. Antes da análise dos dados cada professor teve acesso ao texto transcrito da entrevista para que pudesse validá-la.

Para a interpretação, utilizou-se procedimentos de análise de conteúdo, propostos por Bardin (2011). Esse autor recomenda fases para verificação e procedimentos metodológicos para análise de conteúdo. Assim, aponta três etapas básicas para o uso da análise de conteúdo: a pré-análise, que corresponde à organização do material; a descrição analítica, quando o material de documentos que compõem o corpus é submetido a uma análise aprofundada; e a interpretação referencial. Embora as fases sejam concomitantes e não se apresentem estanques, pois se desenvolvem a partir das necessidades que surgem durante o processo investigativo e estão em movimento durante a pesquisa, com essa visão optou-se por relatar o processo investigativo com a descrição das diferentes fases, mesmo imbricadas umas nas outras. 


\section{Tecendo dados sobre a formação docente e os desdobramentos nas questões didático-pedagógicas dos pesquisados}

Para falar sobre a formação docente, é necessário pensar que a bagagem didáticopedagógica é adquirida ao longo da vida pessoal, escolar, acadêmica e profissional, na qual o professor vivencia, experimenta e constrói seus saberes docentes. Zabalza (2004, p. 131) afirma que "[...] os professores ensinam tanto pelo que sabem como pelo que são", implicando a compreensão de que a qualidade da docência está diretamente ligada aos conhecimentos pedagógicos e específicos da área de atuação, mas também à pessoa do profissional da educação. Essa ideia é reforçada por Nóvoa (1992, p. 17), para quem “[...] a maneira como cada um de nós ensina está diretamente dependente daquilo que somos como pessoa quando exercemos o ensino".

A formação docente pode ser estudada em dois momentos (Nóvoa, 1992; Garcia, 1999): a inicial e a continuada; a primeira ocorre nas universidades, Nóvoa (2017, Entrevista concedida ao Instituto Net Educação) chama atenção para entender que "[...] estas universidades devem estar ligadas à profissão e às escolas, mas este momento é, sobretudo, um momento universitário" e a continuada pode acontecer em diferenciados espaços, tempos e com finalidades específicas.

O professor universitário tem sua formação inicial em cursos de graduaçãolicenciaturas, bacharelados e/ou tecnólogos, mas, para atuar como docente na educação superior, segundo a Lei de Diretrizes e Bases da Educação- LDB (1996), mais especificamente seu art. 66, deve ser preparado em cursos de nível de pós-graduação, prioritariamente em programas de mestrado e doutorado.

Para identificar os professores envolvidos na pesquisa, iniciou-se uma caracterização referente à formação inicial, uma vez que o Ministério da Educação (MEC) e o Conselho Nacional de Educação (CNE) estabelecem que, no nível de graduação, podem ocorrer três formações distintas: a licenciatura, o bacharelado e o tecnólogo, todas com formação, conhecimentos e habilidades diferentes, viabilizando aos profissionais diversas e distintas possibilidades de atuação.

Dos nove professores pesquisados, um professor tinha formação em dois cursos de licenciatura e oito deles eram formados em apenas um curso de bacharelado (Quadro $1)$. 
Quadro 1.

Formação inicial

\begin{tabular}{|l|l|l|}
\hline \multicolumn{1}{|c|}{ Professor } & \multicolumn{1}{|c|}{ Formação inicial } & \multicolumn{1}{c|}{$\begin{array}{c}\text { Tipo de } \\
\text { graduação }\end{array}$} \\
\hline P-DA & Ciências Sociais & Bacharelado \\
\hline P-R & Ciências Sociais & Bacharelado \\
\hline P-D & Ciências Sociais & Bacharelado \\
\hline P-J & Ciências Contábeis & Bacharelado \\
\hline P-T & Comunicação Social - habilitação em Jornalismo & Bacharelado \\
\hline P-M & Comunicação Social - habilitação em Relações Publica & Bacharelado \\
\hline P-E & Química Industrial & Bacharelado \\
\hline P-L & Direito & Bacharelado \\
\hline \multirow{2}{*}{ P-DL } & Pedagogia & Licenciatura \\
\cline { 2 - 3 } & História & Licenciatura \\
\hline
\end{tabular}

Fonte: As autoras (2019).

É importante entender que os cursos de licenciatura são voltados à formação específica de docentes para a educação básica, isto é, para o processo de ensinoaprendizagem da criança e do adolescente. No bacharelado, a formação é voltada para a pesquisa e para o mundo do trabalho, tornando o futuro profissional apto a desenvolver a atividade da área de atuação. Identifica-se que tanto a licenciatura quanto o bacharelado não preparam o docente para atuar na educação superior.

Outro dado levantado foi com relação ao período que frequentaram a graduação, para entender em que contexto social e educacional foram formados. Com esses dados, foi possível inferir que esses professores cursaram a graduação entre as décadas de 1980 e 1990. Uma retrospectiva histórica identifica que, nesse período, as diretrizes contidas na Lei $n^{\circ} 5.540 / 1968$ (Brasil, 1968) orientaram o ensino superior em vigor durante todo o período do governo da Ditadura Militar, sendo a abordagem educacional vigente o tecnicismo e a "[...] Didática, então caberia dispor aos futuros professores os meios e os instrumentos eficientes para o desenvolvimento e o controle do processo de ensinar, visando a maior eficácia nos resultados do ensino" (Pimenta; Anastasiou, 2005, p. 47). Tal pensamento vigorou até 1996, quando foi aprovada a nova LDB.

A formação inicial, segundo Garcia (1999), tem na orientação acadêmica o objetivo de adquirir conhecimentos da área específica de formação para o domínio dos conteúdos e das especificidades da disciplina na qual o professor irá se especializar. Dessa maneira, infere-se que os professores pesquisados tiveram suas formações iniciais fundamentadas na abordagem tecnicista, procedente da corrente positivista, com base na psicologia behaviorista. 
Nessa concepção educacional, o professor tecnicista era identificado como engenheiro comportamental, pois era aquele que controlava, modelava e administrava a educação, usando treinamentos formais, tornando a ação educativa eficiente e eficaz nos resultados da memorização dos conteúdos pelo aluno, considerado inativo ao processo e que apenas recebia, aprendia e fixava as informações. Para Candau (2005, p. 13-14), no modo de ser professor na perspectiva instrumental, os conhecimentos técnicos agiam “[...] sobre o como fazer pedagógico [...] desvinculados dos problemas relativos ao sentido e aos fins da educação, dos conteúdos específicos, assim como do contexto sociocultural concreto em que foram gerados". Dessa forma, a ação do docente era apenas permeada pela técnica, que garantia o sucesso no ensinar e no aprender.

A visão de mundo vai se modificando ao longo do tempo, dessa maneira percebese que a formação realizada na década de 1980 e 1990 por esses professores participantes da pesquisa são bem diferente das necessidades do século XXI, que requer transformações mais profundas, possibilitando uma prática que viabilize pensamentos e ações que compreenda o conhecimento das partes e o todo nas suas inter-relações, que religa, capaz de contextualizar de problematizar em oposição ao pensamento que isola, disjunta e reduz a realidade e o conhecimento (MORIN, 2001).

Como a LDB define que o professor, para atuar na educação superior, deve ser preparado em nível de pós-graduação, investigaram-se primeiramente os cursos de especialização que os participantes frequentaram e se tinham conteúdos e práticas para a formação pedagógica. Os dados coletados (Tabela 1) permitiram identificar que apenas um professor não teve disciplina de cunho didático-pedagógico, enquanto os demais tiveram essa orientação. O resultado positivo com relação aos demais docentes justificase pela Resolução CES no 3/1999 (Brasil, 1999), que exige a oferta de uma disciplina sobre metodologia de ensino nos cursos de pós-graduação lato sensu. Não foi investigado o teor epistemológico e curricular dessas disciplinas, pois o objetivo era somente identificar se o professor, na sua formação continuada, teve algum contato com as questões relacionadas à prática pedagógica.

Tabela 1.

Formação na especialização

\begin{tabular}{|c|c|c|}
\hline Nível & Formação & Quantidade \\
\hline \multirow[t]{3}{*}{ Especialização } & $\begin{array}{l}\text { Sim, tive disciplina de formação didático- } \\
\text { pedagógica. }\end{array}$ & 6 \\
\hline & Não tive disciplina de formação didático-pedagógica & 1 \\
\hline & Não fiz curso de especialização. & 2 \\
\hline
\end{tabular}

Fonte: As autoras (2019). 
Como mencionado, o docente, para atuar na educação superior, deve ser preparado, preferencialmente, em cursos de pós-graduação stricto sensu, mas a LDB não faz menção às questões didático-pedagógicas. Observa-se, no Quadro 2, que apenas um professor fez mestrado na área de educação e dois, doutorado.

Quadro 2.

Áreas de formação no stricto sensu

\begin{tabular}{|l|l|l|}
\hline Professor & \multicolumn{1}{|c|}{ Mestrado - Área } & \multicolumn{1}{c|}{ Doutorado - Área } \\
\hline P-T & Comunicação e Linguagem & Ciências da Educação \\
\hline P-DL & História da Educação & História da Educação \\
\hline P-DA & Administração Estratégica & Não fez \\
\hline P-R & Sociologia & Não fez \\
\hline P-D & Sociologia Política & Não fez \\
\hline P-M & Engenharia de Produção & Não fez \\
\hline P-J & Não fez & Não fez \\
\hline P-E & Não fez & Não fez \\
\hline P-L & Não fez & Não fez \\
\hline
\end{tabular}

Fonte: As autoras (2019).

O levantamento junto aos docentes sobre formação pedagógica no stricto sensu mostrou (Tabela 2) que, no mestrado, três professores fizeram alguma disciplina de cunho didático-pedagógico; no doutorado, nenhum optou por fazê-la. Nesse sentido, “[...] vale salientar que os Programas de Pós-graduação se voltam para a formação de pesquisadores em seus campos específicos e sem exigência quanto à formação pedagógica de professores" (Veiga, 2004, p. 5).

Tabela 2.

Formação no stricto sensu

\begin{tabular}{clc}
\hline Nível & \multicolumn{1}{c}{ Formação } & Quantidade \\
\hline Mestrado & Sim, tive disciplina de formação didático-pedagógica. & 3 \\
& Não tive disciplina de formação didático-pedagógica. & 3 \\
& Não fiz mestrado. & 3 \\
Doutorado & Sim, tive disciplina de formação didático-pedagógica. & 0 \\
& Não tive disciplina de formação didático-pedagógica. & 2 \\
& Não fiz doutorado. & 7 \\
\hline
\end{tabular}

Fonte: As autoras (2019).

A análise da formação inicial e continuada dos pesquisados permitiu identificar que, dos nove professores, seis tiveram disciplinas didático-pedagógicas na especialização e três, no mestrado. São professores, em sua maioria, profissionais liberais, isto é, que têm à docência como uma segunda profissão, pois entendem que seus conhecimentos específicos da área e a experiência profissional no campo de atuação 
fornecem as competências necessárias para atuar como professores na educação superior e que as questões didático-pedagógicas são adquiridas durante a docência.

\section{Investigação sobre o percurso profissional e a reconstrução da prática pedagógica}

Com a identificação de que as questões didático-pedagógicas dos pesquisados oficialmente foram desenvolvidas na formação continuada, buscou-se conhecer teoricamente como se dá a construção da docência influenciada pela carreira profissional, pelas características pessoais, pela referência epistemológica de educação que norteia esse professor, pelo seu percurso de vida profissional, pela sua história de vida, pelas suas ideologias, entre outros aspectos.

A literatura aponta que a construção da prática docente é construída ao longo do tempo e do contexto relacionado com a história de vida e da carreira profissional do professor, em um processo recursivo e retroativo permitindo a autoeco-organização da ação docente, tornando-se formadoras ou transformadoras “[...] quando elas são refletidas e reflexionadas por si ou pelos outros, em uma perspectiva de compreensão e de construção pessoal" (PINEAU; GALVANI, 2012, p.191).

Essa percepção de construção e reconstrução de conhecimentos no sentido de inacabamento permite compreender a complementaridade dos processos, a ressignificação e a superação de questões pessoais e profissionais, na perspectiva de evolução, de reformar o pensamento, pois, para Morin (2001, p. 89), é “[...] preciso substituir um pensamento que isola e separa por um pensamento que distingue e une". $\mathrm{O}$ autor complementa afirmando que "[...] é preciso substituir um pensamento disjuntivo e redutor por um pensamento do complexo, no sentido originário do termo complexus: $\mathrm{o}$ que é tecido junto" (Morin, 2001, p. 89).

Os conhecimentos dos professores estão diretamente relacionados com a dimensão espaço temporal, pelas inúmeras e diferenciadas experiências vividas, que permitem, ao longo da vida pessoal e profissional, atingir transformações que influenciam as ações e o desenvolvimento docente. Alguns estudos clássicos possibilitam compreender fases, transições e crises que podem acontecer na carreira docente, referindo-se a tendências ocorridas em um percurso longitudinal, relacionado, por exemplo, aos anos de experiência docente.

A partir dessas teorias, buscou-se coletar dados para identificar o tempo que os professores pesquisados tinham de docência no ensino superior, no período em que a 
pesquisa foi realizada. Observa-se, na Tabela 3, que dois professores tinham entre um e três anos de docência, dois, entre quatro e seis anos e cinco, entre sete e 25 anos.

Tabela 3.

Tempo de docência na educação superior

\begin{tabular}{ccccc}
\hline 1 a 3 anos & 4 a 6 anos & 7 a 25 anos & 25 a 35 anos & 35 a 40 anos \\
\hline 2 & 2 & 5 & 0 & 0 \\
\hline
\end{tabular}

Fonte: As autoras (2019).

Revisitando as pesquisas de Huberman (2003, p. 38) identificam-se algumas fases relacionadas com a carreira profissional, mas o autor salienta que elas não podem ser vistas de forma fragmentada, linear, com profissionais da mesma profissão passando por todas as etapas, até porque “[...] o desenvolvimento de uma carreira é assim, um processo e não uma série de acontecimentos. Para alguns, esse processo pode parecer linear, mas, para outros, há patamares, regressões, becos sem saída, momentos de arranque, descontinuidades".

Essa ideia pode ser fortalecida com o pensamento complexo, quando se compreende, por meio do princípio do circuito retroativo, que toda causa age sobre um efeito e este age sobre uma causa, modificando-a a partir de processos autorreguladores; ainda, pelo princípio do circuito recursivo ou da auto-organização, os produtos e os efeitos são eles mesmos, produtores e causadores daquilo que os produz (Morin, 2008).

Esses dois princípios da complexidade levam à visão ampliada da carreira vista por Huberman (2003), pois o profissional, neste caso o docente, como sujeito histórico é também influenciado pelos contextos nos quais viveu e está inserido, possibilitando identificar as conexões, os movimentos e descontinuidades, da carreira docente, analisando e pensando a partir de outra lógica , “[...] aprender a perceber e a sentir a partir do que acontece em outros níveis de realidade, aprender a dialogar com as emergências [...] ver um pouco mais adiante daquilo que se revela em um primeiro momento" (MORAES, 2012, p. 77). Esse professor também é produto do conhecimento produzido na sua docência, nas suas relações, interações, retroagindo sobre ele durante cada etapa de seu desenvolvimento, pois o ser e o fazer estão profundamente imbricados.

O ciclo de vida dos professores apresentado por Huberman (2003) é organizado em fases, iniciando com aquela que denominou entrada na carreira, seguida pela fase de estabilização, fase da diversificação, fase de pôr-se em questão, serenidade e distanciamento afetivo, conservadorismo e lamentações e, por fim, fase do desinvestimento. Essas etapas apresentam características que podem ocorrer no percurso 
da carreira docente, auxiliando a compreensão das necessidades dos professores não como homogeneização das atividades, pensamentos, posicionamentos lineares e fixos; em outras palavras, "[...] isto não quer dizer que tais sequências sejam vividas sempre pela mesma ordem, nem que todos os elementos de uma dada profissão as vivam todas" (Huberman, 2003, p. 37), mas que possibilitam compreender o que pode acontecer na carreira do professor no que se refere ao processo de formação docente, que é influenciado também pelas vivências de sua trajetória profissional, pela realidade política institucional na qual está inserido.

Os professores pesquisados estavam na faixa de até 25 anos de experiência de docência na educação superior. Para análise, tomaram-se por referência algumas fases propostas por Huberman (2003):

a. A fase de entrada na carreira explicita sobre a sobrevivência ou o choque com o real, a descoberta e a exploração, ocorrendo entre o primeiro e o terceiro ano de carreira.

b. Na fase de estabilização, que ocorre entre o quarto e o sexto ano de carreira, identificam-se o comprometimento, a responsabilidade, momento em que acontecem o que se pode chamar se tornar um professor e a afirmação do eu.

c. $\quad \mathrm{Na}$ fase de diversificação, o professor, entre o sétimo e o $25^{\circ}$ ano de carreira, permite-se buscar novos desafios, experimentar e diversificar estratégias, recursos, métodos, rompendo com a institucionalização burocrática e paradigmática do contexto universitário.

Analisando essas fases propostas por Huberman (2003), infere-se que o profissional - neste caso o professor da educação superior -, de tempo em tempo, passa por ciclos, como uma reforma do pensamento, o que, para Morin (2001), significa superar a visão reducionista, fragmentadora, linear, para ter novas posturas e comportamentos, posicionamentos influenciados não mais por pensamentos obsoletos e fechados, mas por pensamentos que possibilitem mais um olhar, mais uma percepção, uma atitude de abertura e aprofundamento em relação aos processos de construção e desconstrução do ser professor.

\section{Movimentos realizados pelos professores na carreira docente para reconstrução da prática pedagógica}


Com a informação de que os professores pesquisados construíram sua prática pedagógica tanto pela formação formal - inicial e continuada - quanto pelo seu percurso de vida pessoal e profissional, investigou-se, por meio de questionário, como atuam em sala de aula, a fim de analisar a prática pedagógica, identificando se ela supera a visão tradicional da educação.

No questionário, havia uma questão que pedia para que o professor marcasse todas as opções que retratassem sua docência em sala de aula, incluindo 12 afirmativas alternadas em ações da concepção tradicional de educação e outras elaboradas a partir do pensamento complexo (Quadro 3).

\section{Quadro 3.}

Ações que retratam a docência

\begin{tabular}{|c|c|}
\hline $\begin{array}{l}\text { Ques } \\
\text { tão }\end{array}$ & Alternativas com ações pautadas na concepção tradicional de educação \\
\hline A & $\begin{array}{l}\text { Utilizo alguns recursos tecnológicos (data show, internet, outros) durante a aula, com a } \\
\text { finalidade de facilitar a transmissão dos conteúdos da disciplina. }\end{array}$ \\
\hline $\mathrm{C}$ & $\begin{array}{l}\text { Ensino os conteúdos pressupondo que o aluno irá utilizá-los e aplicá-los no seu dia a dia } \\
\text { conforme foi transmitido. }\end{array}$ \\
\hline $\mathrm{E}$ & $\begin{array}{l}\text { Penso que a participação dos alunos com exemplos e relatos de suas vivências durante as } \\
\text { aulas ocupa muito tempo e impossibilita a transmissão dos conteúdos que são realmente } \\
\text { importantes. }\end{array}$ \\
\hline G & $\begin{array}{l}\text { Como especialista do conteúdo a ser transmitido, atuo como autoridade em sala de aula, } \\
\text { para que os alunos assimilem os conteúdos. }\end{array}$ \\
\hline $\mathrm{H}$ & $\begin{array}{l}\text { Para que eu possa repassar os conteúdos, é necessário que os alunos prestem atenção e } \\
\text { mantenham o silêncio durante minhas explicações, ou seja, preciso manter a disciplina em } \\
\text { sala de aula. }\end{array}$ \\
\hline K & $\begin{array}{l}\text { Com a quantidade de acadêmicos por turma e o número de aulas que tenho na disciplina, } \\
\text { fica muito complicado trabalhar com a individualidade de cada aluno. }\end{array}$ \\
\hline $\begin{array}{l}\text { Ques } \\
\text { tão }\end{array}$ & Alternativas com ações voltadas à superação da concepção tradicional \\
\hline $\mathrm{B}$ & $\begin{array}{l}\text { Mostro ao aluno que o conhecimento está sempre em processo de construção, portanto não } \\
\text { está pronto e acabado, mas se deve concebê-lo como provisório e em transição. }\end{array}$ \\
\hline $\mathrm{D}$ & $\begin{array}{l}\text { Instigo os alunos a produzir seus conhecimentos a partir dos estudos realizados, mediados } \\
\text { por mim }\end{array}$ \\
\hline $\mathrm{F}$ & $\begin{array}{l}\text { Ao planejar minhas aulas, contemplo as diferenças que existem entre os alunos nos seus } \\
\text { estilos e preferências para aprender. }\end{array}$ \\
\hline I & $\begin{array}{l}\text { Para a construção do conhecimento, propicio momentos de diálogo em minhas aulas, } \\
\text { oportunizando a troca entre os alunos e comigo. }\end{array}$ \\
\hline $\mathrm{J}$ & $\begin{array}{l}\text { Considero que o uso da internet, blogs, redes sociais, chat, fórum durante as aulas favorece } \\
\text { a aprendizagem dos conteúdos e a construção do conhecimento pelo aluno. }\end{array}$ \\
\hline $\mathrm{L}$ & Minhas ações em sala de aula estão voltadas para a educação da inteireza, do respeit \\
\hline
\end{tabular}

Fonte: As autoras (2019).

As alternativas com ações pautadas na concepção tradicional de educação foram elaboradas para demonstrar algumas ações da docência que ocorrem em sala de aula, 
sendo que algumas palavras usadas na sua construção manifestam expressões de valorização do domínio exclusivo do professor sobre a questão disciplinar e a reprodução do conteúdo. As demais alternativas foram pautadas na visão do pensamento complexo, que busca o rompimento com a dualidade e alerta contra a fragmentação, o reducionismo e o pensamento linear na produção do conhecimento, propondo a desconstrução de velhos pensamentos, para buscar novos rumos para a prática pedagógica, entendendo que não existe um método a ser seguido, mas um conhecimento a ser lapidado e construído.

As respostas dos docentes permitiram levantar sua concepção, como retratado na Tabela 4.

Tabela 4.

Ações na prática pedagógica

\begin{tabular}{|c|c|c|c|c|c|c|c|c|c|c|c|c|c|c|}
\hline \multirow[b]{2}{*}{ Prof. } & \multicolumn{5}{|c|}{$\begin{array}{l}\text { Ações pautadas } \\
\text { tradicional }\end{array}$} & \multicolumn{2}{|c|}{ na concepção } & \multicolumn{7}{|c|}{$\begin{array}{l}\text { Ações voltadas à superação da } \\
\text { concepção tradicional }\end{array}$} \\
\hline & A & $\mathrm{C}$ & $\mathrm{E}$ & G & $\mathrm{H}$ & K & Total & B & $\mathrm{D}$ & $\mathrm{F}$ & I & $\mathrm{J}$ & $\mathrm{L}$ & Total \\
\hline P-DA & 1 & 1 & & & 1 & 1 & 4 & 1 & 1 & & 1 & 1 & 1 & 5 \\
\hline P-J & 1 & 1 & & & & 1 & 3 & 1 & 1 & 1 & 1 & 1 & 1 & 6 \\
\hline P-R & 1 & 1 & & & 1 & & 3 & 1 & 1 & 1 & 1 & & 1 & 5 \\
\hline P-D & & 1 & & & & 1 & 2 & 1 & 1 & & 1 & & 1 & 4 \\
\hline P-M & 1 & 1 & & & & & 2 & 1 & 1 & 1 & 1 & 1 & 1 & 6 \\
\hline P-T & 1 & & & & & & 1 & 1 & & 1 & 1 & & & 3 \\
\hline P-L & 1 & 1 & & & 1 & 1 & 4 & 1 & 1 & & 1 & & 1 & 4 \\
\hline P-DL & 1 & & & 1 & 1 & 1 & 4 & & 1 & & & & 1 & 2 \\
\hline P-E & 1 & & & & & 1 & 2 & 1 & 1 & 1 & 1 & & & 4 \\
\hline $\begin{array}{l}\text { Total parcial } \\
\text { TOTAL }\end{array}$ & 8 & 6 & 0 & 1 & $\begin{array}{l}4 \\
25\end{array}$ & 6 & & 8 & 8 & 5 & 8 & $\begin{array}{l}3 \\
35\end{array}$ & 7 & \\
\hline
\end{tabular}

Fonte: As autoras (2019).

Observando a Tabela 4, identifica-se que os professores selecionaram, das ações que realizam dentro de sala de aula, aquelas mais pautadas na superação da concepção tradicional, num total de 39 ações. Nesse sentido, percebe-se que os docentes buscam instigar em seus alunos o aprender a aprender, viabilizando novos questionamentos, novos caminhos, aprender com o erro, saber suas possibilidades e limites, aprender a administrar seus sentimentos, respeitar a individualidade e a diversidade, participar de projetos comuns, trabalhar simultaneamente com a razão e a emoção, ações que coadunam com as exigências da contemporaneidade.

Outro aspecto que chama atenção é que oito professores escolheram a alternativa A, referente à utilização de alguns recursos tecnológicos na prática pedagógica, porém a finalidade do professor é transmitir o conteúdo e não empregar tais recursos como mediação da produção do conhecimento. Essa escolha mostra um ensino com ação 
pedagógica conservadora, predominando um aluno passivo que, muitas vezes, continua apenas escutando, repetindo e reproduzindo os conteúdos transmitidos pelos docentes.

O mundo no qual se vive está em constante transformação e autocriação, sendo marcado por incertezas, provisoriedade e transitoriedade, com o desenvolvimento acelerado dos conhecimentos e das tecnologias. Essa visão pode ser identificada na docência de oito professores, conforme registrado na Tabela 4Erro! Fonte de referência não encontrada..

\section{Reflexões sobre a prática pedagógica e o repensar na docência}

Nesta fase, buscou-se dialogar com os professores durante a entrevista para que refletissem especificamente sobre ações que poderiam ser repensadas na docência e o porquê. Pediu-se para que dissessem quais ações na prática pedagógica caracterizam uma concepção conservadora de educação; assim alguns se manifestaram:

A questão da relação em sala de aula, estudantes, professor e aluno, mantendo dessa forma uma relação de autoridade, professor e aluno, disciplina, a não empatia do estudante com o professor (P-D).

Aquela pautada na reprodução de conteúdo previamente estabelecidos (P-T).

Eu acho que o tradicional é simplesmente ministrar um conteúdo sempre [...] utilizar uma aula tradicional eu acho que isso é só reproduzir mesmo, pegar um livro de teoria e reproduzir sem saber em que eles podem utilizar aquilo, adequar aquilo e me preocupar com o interesse deles, eu acho que é isso (P-J).

A aula expositiva caracteriza um ensino tradicional, pois é o professor quem tem o conteúdo, o aluno está lá para aprender (P-DA).

Ações que caracterizem ações tradicionais, para mim acho que a questão da avaliação está diretamente ligada a isso [...]. A prova, aquele momento ali fechado, único para o aluno, eu acho que isso fecha muito e também a postura do professor de se colocar como o detentor do saber, ele é que sabe, ele é o todo-poderoso, de se colocar em cima do tablado e o aluno tem que absorver o que ele está passando, eu acho que isso caracteriza fortemente a avaliação e a postura do professor também (P-DL).

Utilização do quadro-negro, a própria explanação oral da disciplina, o professor sendo uma autoridade perante os alunos, isso é uma tradição (P-L).

São aqueles alunos quietinhos olhando a gente e a gente usando o quadro, falando e explicando e isso eu acho monótono e chato (P-M).

Os docentes, em suas afirmações, expressaram atitudes como a autoridade e postura do professor detentor do conhecimento, a questão da disciplina exigida em sala de aula, os professores como transmissores e reprodutores de conteúdos predefinidos, a utilização da aula expositiva como uma tradição pelo uso do quadro-negro e pela 
explanação oral, a prova como reprodução dos conteúdos ministrados na sala de aula e o aluno passivo.

O que se observa nos depoimentos são posturas que retratam pressupostos da abordagem tradicional, como também da tendência tecnicista. A esse respeito, Libâneo (1990), Mizukami (1986) e Behrens (2005) mencionam que o professor exige disciplina para assegurar a atenção e o silêncio, sendo o administrador das condições de transmissão da matéria, buscando eficiência e eficácia nos resultados de aprendizagem, sendo a base do ensino os conteúdos observáveis e mensuráveis. Esses autores afirmam ainda que o ensino é centrado no professor, que ministra aulas expositivas e demonstrativas, com exercícios de repetição, aplicação e recapitulação de conteúdos prontos e acabados, como pode ser verificado no depoimento dos pesquisados.

Nas respostas de alguns professores, percebe-se a tendência para a reflexão, uma vez que citaram reelaborar suas práticas a partir das experiências da prática pedagógica ocorridas nos períodos anteriores, além de refletir sobre suas ações durante a aula. Verificam-se aspectos da prática reflexiva de Schön (2000), de reflexões desencadeadas na e sobre a ação, dos quais se destacaram algumas posições:

Eu frequentemente procuro estar sempre repensando; a partir do momento que eu escolhi o ensino como profissão, eu entendo que as nossas práticas de certa forma ficam em desuso, não são eficientes para trabalhar no ensino-aprendizagem. Então uma geração de um ano atrás é totalmente diferente de uma geração de hoje ( $\mathrm{P}-\mathrm{D}$, grifos nossos).

Na minha prática pedagógica eu a repenso cotidianamente, eu sou um crítico da escola como ela é hoje e da minha atuação como professor inclusive, porque ela está inserida na estrutura atual do ensino. E eu acho que o ensino está quase 100\% errado do começo ao fim. Eu sou um crítico do modelo atual pedagógico, desde a concepção das salas de aula, como elas são fisicamente hoje, até o papel do professor, da predefinição de matérias, para mim está tudo errado. Eu acho que o ensino deveria ser totalmente diferente do que é hoje ( $\mathrm{P}-\mathrm{T}$, grifos nossos).

Sempre, a cada semestre onde determina, eu vou ministrar a mesma disciplina no próximo semestre e ainda assim eu repenso a forma e eu acho que cada turma tem uma característica, tem um perfil. Então a cada semestre, de acordo com o perfil da turma, com quantitativo da turma, eu vou rever o que eu vou utilizar de metodologia (P-J, grifos nossos).

Na minha prática pedagógica eu sempre penso e sempre me reposiciono todo semestre com os alunos, pensando essa relação ensino-aprendizagem. Minha postura é eu abrir muito, discutir o como fazer (P-DL, grifos nossos).

Eu me vejo, não sei se posso dizer isso, mas eu me vejo como uma pessoa que está aberta à modernidade e eu procuro a cada etapa fazer diferente, porque, a partir do momento que você vê uma reação dos alunos, você tem que mudar e é isso que eu busco sempre. Cada turma é diferente, às vezes você pensa dar a mesma aula para várias turmas e quando você chega você vê que não é, muda, e tem que estar preparado para essa mudança (P-L, grifos nossos).

Sempre há algo a ser repensado. Eu não sei agora falar algo que eu precise repensar. Mas quando acontece algum problema, mesmo que seja com algum aluno pontualmente, eu procuro descobrir 
as razões daquele problema e com certeza eu acabo tendo que mudar algo em mim, na minha postura como professora ou na minha aula (P-M, grifos nossos).

Nos depoimentos dos professores, percebem-se pontos de interseção com a teoria de Schön (2000), de que a reflexão na ação pressupõe um refletir, um pensar, um intervir durante a ação pedagógica, permitindo um novo direcionamento, produção ou reestruturação do conhecimento, possibilitando que o docente perceba que pode tomar decisões na hora em que sua prática pedagógica está sendo desenvolvida, podendo acontecer antes ou depois da ação - aula -, oportunizando, além da reflexão, dialogar com seus pares e/ou com seus alunos.

A complexidade de Morin $(1999,2001,2008)$ sinaliza que o sujeito - docente - é o autor de sua história e corresponsável pelo seu aprendizado, pelo seu desenvolvimento, pela ressignificação do que aprende e do que faz em sua prática pedagógica. O sujeito não é apenas indivíduo solitário, mas vive coletivamente e faz parte de uma sociedade, sendo produto de suas interações e aberto às trocas com o meio em que habita.

Considerando que na prática pedagógica de sala de aula as ações do professor são influenciadas por aquilo que acontece no ambiente de aprendizagem, isto é, nas interações entre os indivíduos, entre esses e os objetos e com o meio, e que a partir dessas interações a docência é influenciada, incorporando os conceitos, pensamentos, sentimentos, atitudes e procedimentos que emergem desse processo de inter-relações, retroações e cooperação, há o entendimento do que é denominado princípio ecológico da ação ${ }^{1}$.

Esse princípio leva a entender que toda ação e reação na educação não se dão linearmente, mas estão em movimento e são imprevisíveis. A partir do instante em que uma ação é planejada, ela interage com outras situações e acontecimentos do meio ambiente e pode se tornar algo não pensado primeiramente ou até mesmo contrário do que se pretendeu. É um movimento contínuo de ir e vir, pois as inter-relações e retroações ocorridas na sala de aula são como um circuito contínuo que varia de acordo com o que ocorre nos processos autoeco-organizadores e os resultados gerados por essas interrelações e retroações. Assim, a formação pedagógica dos professores universitários necessita ser continua e contemplar contribuições renovadas e inovadoras para o desenvolvimento da ação docente que corresponda às necessidades desafiadoras da educação para o século XXI.

\footnotetext{
${ }^{1}$ Faz parte dos operadores cognitivos do pensamento complexo definido por Morin (2000).
} 


\section{Considerações finais}

A abordagem da educação tradicional gerou a visão de que o docente é o único detentor dos conteúdos e responsável direto pela transmissão dos conteúdos prontos e acabados, enquanto os alunos são vistos como reprodutores de conteúdo. A superação dessa prática pedagógica exige, na visão de Behrens e Prigol (2019, p. 81), que se "privilegiem o questionamento, a dúvida, a participação, o debate, a resolução de problemas, a comparação de teorias, autores e princípios, a construção de análise e sínteses, fazendo o aluno pensar, refletir, criar e desenvolver sua autonomia", as autoras complementam afirmando que a ação docente deve "oportunizar a relação entre o conhecimento existente e o novo, permitindo ao aluno construir seu próprio conhecimento com significado, fazer inferências e generalizações, identificar diferentes pontos de vista sobre o conteúdo aprendido".

A exigência na atualidade altera a relação professor-aluno, instigando o diálogo amoroso (Freire, 1992), para a parceria, a proposição de trabalhos coletivos em uma relação horizontal, o compartilhamento de ideias, a produção coletiva do conhecimento, exigindo do docente flexibilidade, visão ampliada e compreensão da provisoriedade, da complexidade e da docência de qualidade.

Identificou-se que existem muitas aproximações, como também algumas divergências nos pensamentos e ações dos professores durante sua carreira, quando feita a comparação entre o ciclo de vida do docente (Huberman, 2003) e as ações e pensamentos dos professores. Nesse percurso, que vai de dois anos para o professor mais novo a 13 anos para o professor com mais experiência, infere-se que eles ainda são influenciados pela concepção conservadora da educação, mas, ao mesmo tempo, buscam ao longo da docência reelaborar seus conhecimentos, entendendo que é um processo permanente de desenvolvimento, que necessita de uma postura reflexiva para que possam reconstruir sua ação didática, por intermédio de processos de aprendizagem, seja individual, seja socialmente, utilizando os meios, o tempo e o espaço mais apropriados para suas necessidades.

A instituição de educação superior, ao mesmo tempo, mantém a tradição e inova, “[...] conserva, memoriza, integra e ritualiza uma herança cultural de saberes, ideias e valores, que acaba por ter um efeito regenerador, porque a universidade se incube de reexaminá-la, atualizá-la e transmiti-la” (Morin, 2000, p. 9-10), sendo tanto um local 
conservador quanto reconstrutor de conhecimentos, buscando transcender a visão paradigmática conservadora e ir além da visão fragmentada de disciplinaridade e, assim, buscar caminhos interdisciplinares e transdisciplinares na ação docente.

Por esse viés, o professor precisa compreender que o ensino significativo necessita da superação da fragmentação, da divisão e da compartimentalização. A prática pedagógica precisa estar relacionada ao desenvolvimento e transformação dos indivíduos e, nesse caso, os docentes, sendo um dos profissionais mais importantes para a efetivação dessa demanda, devem se propor a participar de processos formativos pedagógicos contínuos em busca da renovação da ação docente que venha às exigências da sociedade no século XXI.

\section{Referências}

Bardin, L. (2011). Análise de conteúdo. São Paulo: Edições 70.

Behrens, M. A. (2005). O paradigma emergente e a prática pedagógica. Petrópolis: Vozes.

Behrens, M. A.; Prigol, E. L. (2019). Prática docente: das teorias críticas à teoria da complexidade. In: Ricardo Antunes de Sá e Marilda Aparecida Behrens. (Org.). Teoria da complexidade. Contribuições epistemológicas e metodológicas para uma pedagogia complexa. Curitiba: Appris. v. 1, p. 65-86.

Brasil. (1968). Lei no 5.540, de 28 de novembro de 1968. (1968, 28 de novembro). Fixa normas de organização e funcionamento do ensino superior e sua articulação com a escola média, e dá outras providências. Recuperado em 20 de junho, 2019, de http://www.planalto.gov.br/ccivil_03/leis/L5540.htm.

Brasil. (1996). Lei no 9.394, de 20 de dezembro de 1996. (1996, 20 de dezembro). Estabelece as diretrizes e bases da educação nacional. Recuperado em 20 de junho, 2019, de http://www.planalto.gov.br/ccivil_03/Leis/L9394.htm.

Brasil. (1999). Resolução CES no 3, de 5 de outubro de 1999. Fixa condições de validade dos certificados de cursos presenciais de especialização. Recuperado em 20 de junho, 2019, de http://portal.mec.gov.br/cne/arquivos/pdf/rces03_99.pdf.

Candau, V. M. (Org.). (2005). Rumo a uma nova didática (16. ed.). Petrópolis: Vozes.

Chizzotti, A. (2003). Pesquisa em ciências humanas e sociais (6. ed.). São Paulo: Cortez.

Denzin, Norman K; Lincoln, Yvonna S. O. Planejamento da Pesquisa Qualitativa: Teorias e Abordagens. Porto Alegre: Artmed, 2006. 
Freire, P. (1992). Pedagogia da esperança. Rio de Janeiro: Paz e Terra.

Huberman, M. (2003). O ciclo de vida profissional dos professores. In A. Nóvoa. Vida de professores. Porto: Porto.

Garcia, M. C. (1999). Formação de professores: para uma mudança educativa. Porto: Porto.

Libâneo, J. C. (1990). Democratização da escola pública: a pedagogia crítico-social dos conteúdos. (9. ed.) São Paulo: Loyola.

Mizukami, M. G. N. (1986). Ensino: as abordagens do processo. São Paulo: EPU.

Moraes, M. C. (1997). Paradigma educacional emergente. Campinas: Papirus.

Moraes, M.C. (2012). Transdisciplinaridade e educação. In: Formação de professores: elos da dimensão complexa e transdisciplinar. Goiana: Ed. Da PU Goiás, 2012.

Morin, E. (2012). Os sete saberes necessários à educação do presente. In: MORAES, M. C. ALMEIDA, M.C. (org.). Os sete saberes necessários para a educação do futuro. Por uma educação transformadora. RJ: Wak Editora.

Morin, E. (2008). A cabeça bem-feita: repensar a reforma, reformar o pensamento. RJ: Bertrand Brasil.

Morin, E. (1999). Ciência com consciência. Rio de Janeiro: Bertrand.

Morin, E. (2001). A cabeça bem-feita: repensar a reforma, reformar o pensamento. Rio de Janeiro: Bertrand Brasil.

Nóvoa, A. (1992). Profissão professor. Porto: Porto.

Nóvoa, António. (2017). Entrevista concedida ao Instituto Net Educação. Disponível em: https://www.youtube.com/watch?v=KqopJQO3K0E Acesso em: 8/04/2020.

Pimenta, S. G., \& Anastasiou, L. G. (2005). Docência no ensino superior (2. ed.). São Paulo: Cortez.

Pineau, G.; Galvani, P. (2012). Experiências de vida e formação docente: Religando saberes. In: Maria Cândida Moraes e Maria da Conceição de Almeida (Org.). Os Sete Saberes Necessários à Educação do Presente: por uma educação transformadora. Rio de Janeiro: WAK Editora.

Schön, D. (2000). Educando o profissional reflexivo: um novo design para o ensino e a aprendizagem. Porto Alegre: Artmed.

Veiga, I. P. (2004). A universidade no século XXI. São Paulo: Cortez. 
Yin, R., \& Grassi, D. (2001). Estudo de caso: planejamento e métodos (2. ed.). Porto Alegre: Bookman.

Zabalza, M. (2004). O ensino universitário: seu cenário e seus protagonistas. Porto Alegre: Artmed.

Submetido: 23/09/2019

Aprovado: 30/04/2020 